\title{
Glucocorticoid-induced diabetes in patients with metastatic spinal cord compression
}

\author{
Helga Schultz' ${ }^{1}$, Svend Aage Engelholm²,3, Eva Harder ${ }^{4}$, Ulrik Pedersen-Bjergaard ${ }^{1,3}$ and \\ Peter Lommer Kristensen ${ }^{1}$ \\ 1'Department of Cardiology, Nephrology and Endocrinology, Nordsjællands Hospital, Hillerød, Denmark \\ 2Department of Radiation Oncology, Rigshospitalet, Copenhagen, Denmark \\ ${ }^{3}$ Faculty of Health and Medical Sciences, University of Copenhagen, Copenhagen, Denmark \\ ${ }^{4}$ Department of Oncology and Palliation, Nordsjællands Hospital, Hillerød, Denmark
}

Correspondence should be addressed to P L Kristensen: peter.lommer.kristensen.01@regionh.dk

\begin{abstract}
Background: The risk of developing diabetes mellitus (DM) during treatment with highdose glucocorticoids is unknown and monitoring of glucose is random in many settings. Objective: To determine incidence of and risk factors for induction of DM during high-dose glucocorticoid therapy of metastatic spinal cord compression (MSCC) in patients referred to radiotherapy. Furthermore, to describe the time course of development of DM.

Subjects and methods: 140 patients were recruited (131 were included in the analysis) with MSCC receiving high-dose glucocorticoid $\geq 100 \mathrm{mg}$ prednisolone per day were included in a prospective, observational cohort study. The primary endpoint was development of DM defined by two or more plasma glucose values $\geq 11.1 \mathrm{mmol} / \mathrm{L}$. Plasma glucose was monitored on a daily basis for 12 days during radiotherapy. Results: Fifty-six of the patients $(43 \% ; 95 \% \mathrm{Cl} 35-52 \%)$ were diagnosed with DM based on plasma glucose measurements during the study period. Sixteen patients, $12 \%(95 \%$ $\mathrm{Cl}$ 6-18\%), were treated with insulin. At multivariate analysis, only high baseline $\mathrm{HbA} 1 \mathrm{c}$ predicted the development of insulin-treated DM. An HbA1c-value $<39 \mathrm{mmol} / \mathrm{mol}$ was associated with a negative predictive value of $96 \%$ for not developing DM needing treatment with insulin. The diagnosis of diabetes with need for insulin treatment was made within 7 days in 14 of the 16 (88\%; 95\% Cl $72-100 \%)$ patients.

Conclusion: The risk of developing DM during treatment with high-dose glucocorticoids in patients with MSCC referred to radiotherapy is high in the first treatment week. Only referral $\mathrm{HbA1c}$ predicts the development of DM.
\end{abstract}

\author{
Key Words \\ - glucocorticoid \\ - diabetes \\ - metastatic spinal cord \\ compression (MSCC)
}

Endocrine Connections (2018) 7, 719-726

\section{Introduction}

In patients with malignant disease, glucocorticoids are widely used on various indications. High-dose treatment is given as part of chemotherapy regimens and for treating oedema associated with metastatic spinal cord compression (MSCC) and brain tumours. Diabetes mellitus (DM) is a well-known metabolic side effect from treatment with glucocorticoids. The diabetogenic effect is mainly a result of insulin resistance in muscle and fatty tissue, increased production of glucose from the liver, and eventually also impaired beta-cell function (1). Hyperglycaemic symptoms may impair patients' well-being and with more severe hyperglycemia, they may become catabolic and more susceptible to infections and impaired wound healing. Undiagnosed or untreated DM may ultimately develop into potentially fatal hyperglycaemic hyperosmolar state $(2,3)$. Furthermore, glucocorticoid-induced

$$
\begin{array}{lr}
\text { http://www.endocrineconnections.org } & \text { O2018 The authors } \\
\text { https://doi.org/10.1530/EC-18-0088 } & \text { Published by Bioscientifica Ltd }
\end{array}
$$

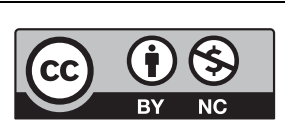

This work is licensed under a Creative Commons Attribution-NonCommercial 4.0 International License. 
hyperglycemia during chemotherapy has been associated with a poorer prognosis such as a shorter remission period, a shorter median survival and a higher rate of side effects to the antineoplastic therapy (4).

Despite the potential clinical significance, there are only scarce data on incidence of and risk factors for development of DM during high-dose glucocorticoid therapy in cancer patients. Thus, only two retrospective studies both hampered by lack of systematic screening and lack of data on the actual screening intensity have reported the incidence in the range from 13\% to $37 \%$ $(4,5)$. In these studies, development of DM during glucocorticoid therapy was inconsistently associated with age, thrombocytopenia and dose of glucocorticoid. Furthermore, the time course for development of glucocorticoid-induced DM is not well described.

The current lack of knowledge in the field is reflected by the fact that there are no generally accepted guidelines for screening for and handling of DM occurring during treatment with glucocorticoids. Accordingly, The Joint British Diabetes Societies for Inpatient Care and the American Endocrine Society have made each their suggestions, both based on a low level of evidence $(6,7)$.

Therefore, we conducted a prospective, observational study in order to determine the incidence and the time course of development of DM in patients without previously known DM with MSCC receiving highdose glucocorticoid therapy. We also aimed to identify potential risk factors.

\section{Subjects and methods}

\section{Design}

From May 2013 to December 2014, we conducted a prospective, observational cohort study including patients from the Department of Radiation Oncology at Rigshospitalet, Copenhagen. Patients with a tentative diagnosis of MSCC are referred to the unit $24 \mathrm{~h}$ a day 7 days a week from an area with approximately 2.4 million inhabitants. If the diagnosis of MSCC is confirmed, the patient is offered either radiotherapy alone or surgical decompression followed by radiotherapy. High-dose glucocorticoid therapy has been proven beneficial as an adjunct to radiotherapy (8) and is most often initialised at the local hospital, alternatively prescribed at the first visit at Rigshospitalet. The study was approved by The National Committee on Health Research Ethics (file number H-42012-004) and reported to the Danish Data Protection

$$
\begin{array}{lr}
\text { http://www.endocrineconnections.org } & \text { @2018 The authors } \\
\text { https://doi.org/10.1530/EC-18-0088 } & \text { Published by Bioscientifica Ltd }
\end{array}
$$

Agency (file number HIH-2011-22). All participants gave their written informed consent.

\section{Subjects}

Patients with a histologically confirmed cancer diagnosis were eligible for inclusion if they were aged 18 years or more, were diagnosed with MSCC, treated with $\geq 100 \mathrm{mg}$ prednisolone daily and were referred to radiotherapy treatment with 30 Grey in 10 fractions. Known DM was the only exclusion criterion. We chose not to exclude patients due to other reasons since we wanted to do a 'real-life' study.

\section{Clinical and laboratory data}

At the time of inclusion, we obtained information on height and body weight, medical history, DM in first- and second-degree relatives, tobacco and alcohol consumption and medications data. Venous blood samples were collected for analysis of $\mathrm{HbA1c}$, C-peptide, lipids and plasma glucose. HbA1c was measured using a commercial liquid chromatography analysis, normal range $<48 \mathrm{mmol} / \mathrm{mol}$. Other analyses were done by standard methods. Performance status (PS) was assessed using the toxicity and response criteria of the Eastern Cooperative Oncology Group (ECOG) (9). On the last day of radiotherapy, venous blood samples for measurement of HbA1c, C-peptide, lipids and plasma glucose were repeated. The dose of prednisolone was registered on a daily basis.

\section{Screening procedure}

The subsequent 12 days after inclusion one to four capillary blood glucose measurements daily were performed using a Medisense Precision XceedPro Glucosemeter (Abbott Diabetes Care). In inpatients, we aimed at three measurements a day in their local hospital and one measurement in the Section of Radiotherapy, while outpatients had one measurement in conjunction with radiotherapy. The time of the daily glucose measurements depended on local guidelines and the scheduled radiotherapy.

\section{Endpoints}

The primary endpoint was DM defined as two random plasma glucose measurements $\geq 11.1 \mathrm{mmol} / \mathrm{L}$. The WHO diagnostic criteria for $\mathrm{DM}$ are fasting plasma glucose $\geq 7.0 \mathrm{mmol} / \mathrm{L}$ or 2 -h plasma glucose $\geq 11.1 \mathrm{mmol} / \mathrm{L}$, but as



This work is licensed under a Creative Commons Attribution-NonCommercial 4.0 International License. 
neither fasting glucose measurements nor an oral glucose tolerance test was feasible in the setting of this study, we chose the above mentioned definition (10). Due to the short time of observation, DM defined by HbA1c was not considered feasible. The secondary endpoint was the number of patients, who started treatment with insulin. There were no study instructions about the initiation of insulin treatment. This decision was taken only by the doctors at the department to which the patient was admitted. Patients were defined as having insulin-treated DM from their first injection of insulin.

\section{Statistics}

A sample size of 140 participants was calculated from an expected prevalence of DM of $15 \%$ with an accuracy of $\pm 5 \%$. Standard statistical tests were used to compare demographic and diabetes-related parameters. To identify risk factors for developing DM requiring insulin treatment, univariate and multivariate logistic regression analyses were done. Known risk factors for type 2 diabetes (BMI, sex, age, having a first- or second-degree relative with DM) and variables associated with developing DM in the univariate analysis $(P<0.15)$ were included in the multivariate analysis. A $P$-value (two sided) $\leq 0.05$ was considered statistically significant. Data were analysed using the SPSS software application (version 19.0 and 22.0).

\section{Results}

\section{Recruitment/response}

Of 324 patients assessed for eligibility, 140 were recruited (43\%) and 131 were included in the analysis (Fig. 1).

We followed 109 (83\%) of the patients for 12 days, and 22 patients (17\%) for 6-11 days as calculated from the day of prednisolone initiation until the last blood glucose measurement.

The median number of plasma glucose measurements per patient was 24 (IQR 15-32) in fully hospitalised patients, 11 (IQR 8-17) in patients partially hospitalised and 8 (IQR 7-9) in outpatients.

There was no association between the number of blood glucose measurements and the detection of DM.

\section{Characteristics of the sample}

Baseline characteristics of the participants are presented in Table 1 . The study population resembles the overall

$$
\begin{aligned}
& \text { http://www.endocrineconnections.org } \\
& \text { https://doi.org/10.1530/EC-18-0088 }
\end{aligned}
$$

C2018 The authors Published by Bioscientifica Ltd

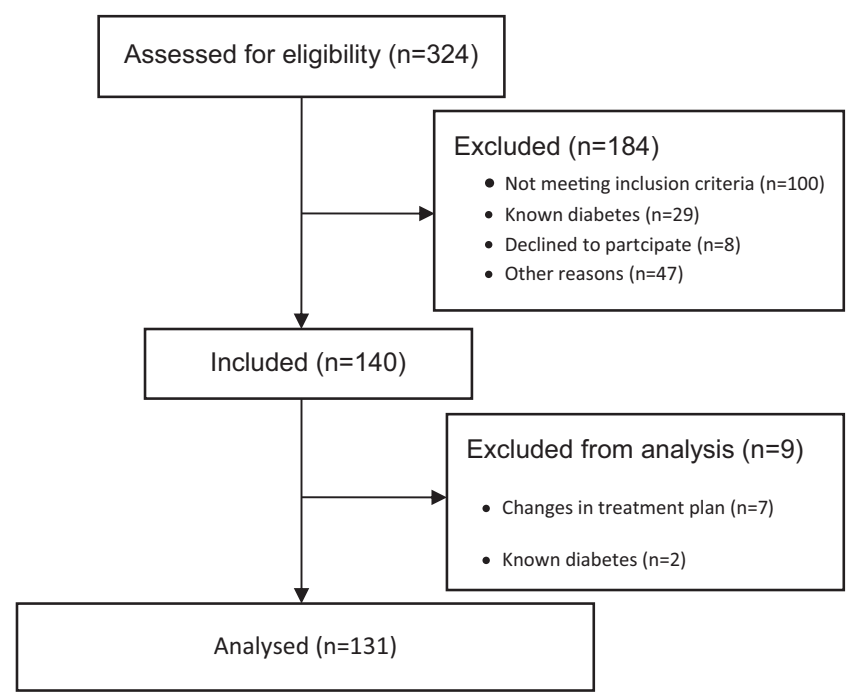

Figure 1

Consort diagram.

population of MSCC patients referred to Rigshospitalet with regard to sex, age and oncological diagnosis (11).

Incidence and time course of development of diabetes

During follow-up a total of 56 patients (43\%; 95\% CI $35-52 \%)$ presented plasma glucose values diagnostic of DM. Sixteen patients developing DM were treated with insulin, $12 \%$ (95\% CI 6-18\%) of the total population and $29 \%$ (95\% CI 21-37\%) of the patients with a diagnosis of DM (Table 1).

The incidence of DM left untreated rose steadily throughout the observation period. In contrast, the need for insulin therapy was decided within 7 days after the diagnosis of DM in 14 of the 16 (88\%; 95\% CI 72-100\%) insulin-treated patients (Fig. 2).

In Fig. 3, the plasma glucose values are plotted against time of the day according to groups of DM status. Plasma glucose was highest in the afternoon in all the three groups of patients. In a mixed model performed separately for each group (no DM, untreated DM and insulin-treated $\mathrm{DM})$ the level of glucose depended on time of day in all three groups $(P<0.001$ in all groups).

\section{Baseline HbA1c as predictor for insulin-treated with insulin}

Six of the 131 patients (5\%; 95\% CI 1-9\%) had a slightly elevated $\mathrm{HbA} 1 \mathrm{c}$ value at baseline $(49-57 \mathrm{mmol} / \mathrm{mol})$. Of these, 3 developed insulin-treated DM, 3 developed 
Table 1 Baseline characteristics of the entire cohort and according to outcome.

\begin{tabular}{|c|c|c|c|c|}
\hline Variable & All & No diabetes & Untreated diabetes & $\begin{array}{l}\text { Diabetes treated } \\
\text { with insulin }\end{array}$ \\
\hline$N(\%)$ & $131(100)$ & $75(57)$ & $40(31)$ & $16(12)$ \\
\hline Female sex (\%) & 42 & 43 & 45 & 31 \\
\hline Age (years), min-max & $68(46-88)$ & $68(48-88)$ & $68(46-87)$ & $69(50-86)$ \\
\hline BMI $\left(\mathrm{kg} / \mathrm{m}^{2}\right), \min -\max$ & $25(14-44)$ & $\begin{array}{c}25(15-44) \\
\quad N=73\end{array}$ & $\begin{array}{c}24(14-31) \\
\quad N=38\end{array}$ & $\begin{array}{c}25(18-33) \\
\quad N=15\end{array}$ \\
\hline \multicolumn{5}{|l|}{ Performance status (\%) } \\
\hline 0 & $6(4)$ & $6(8)$ & 0 & $0(0)$ \\
\hline 1 & $52(40)$ & $36(48)$ & $13(32)$ & $3(19)$ \\
\hline 2 & $44(34)$ & $18(24)$ & $19(48)$ & $7(44)$ \\
\hline 3 & $29(22)$ & $15(20)$ & $8(20)$ & $6(37)$ \\
\hline \multicolumn{5}{|l|}{ Primary tumour (\%) } \\
\hline Lung & $36(27)$ & $22(29)$ & $10(25)$ & $4(25)$ \\
\hline Breast & $25(19)$ & $16(21)$ & $7(17)$ & $2(13)$ \\
\hline Prostate & $31(24)$ & $14(19)$ & $12(30)$ & $5(31)$ \\
\hline Others & $39(30)$ & $23(31)$ & $11(28)$ & $5(31)$ \\
\hline Brain metastases (\%) & $5(4)$ & $4(5)$ & 0 & $1(6)$ \\
\hline Lung metastases (\%) & $51(39)$ & $35(47)$ & $13(33)$ & $3(19)$ \\
\hline Liver metastases (\%) & $30(23)$ & $16(21)$ & $9(23)$ & $5(31)$ \\
\hline Bone metastases $(\%)$ & $129(99)$ & $74(99)$ & $39(98)$ & $16(100)$ \\
\hline Pancreatic metastases (\%) & 0 & 0 & 0 & 0 \\
\hline Alcohol abuse now or earlier (\%) & $26(20)$ & $14(19)$ & $9(23)$ & $3(19)$ \\
\hline Smoking, now or earlier (\%) & $88(67)$ & $52(69)$ & $27(68)$ & $9(56)$ \\
\hline Antihypertensive therapy (\%) & $52(40)$ & $30(40)$ & $16(40)$ & $6(38)$ \\
\hline Lipid lowering therapy (\%) & $27(21)$ & $19(25)$ & $6(15)$ & $2(13)$ \\
\hline Atheroschlerosis (\%) & $17(13)$ & $10(13)$ & $4(10)$ & $3(19)$ \\
\hline Liver disease (\%) & $3(2)$ & $7(9)$ & $1(3)$ & 0 \\
\hline Thyroid disease (\%) & $11(8)$ & $7(9)$ & $3(8)$ & $1(6)$ \\
\hline Pancreatic disease (\%) & $2(2)$ & $1(1)$ & $1(3)$ & 0 \\
\hline \multicolumn{5}{|l|}{ Hospitalisation or not } \\
\hline Outpatient & $56(43)$ & $41(55)$ & $15(38)$ & 0 \\
\hline Inpatient & $53(40)$ & $21(28)$ & $19(47)$ & $13(81)$ \\
\hline Alternating & $22(17)$ & $13(17)$ & $6(15)$ & $3(19)$ \\
\hline Prednisolone start dose (mg), mean (min-max) & $261(100-2500)$ & $234(100-350)$ & $307(100-2500)$ & $275(150-300)$ \\
\hline $\begin{array}{l}\text { Cumulated dose of prednisolone }(\mathrm{mg}), \text { mean } \\
(\min -\max )\end{array}$ & $2919(1000-6750)$ & $2835(1200-3650)$ & $3040(1000-6750)$ & $2966(1400-3600)$ \\
\hline Daily prednisolone dose (mg), mean (min-max) & $247(83-563)$ & $240(100-304)$ & $255(83-563)$ & $259(150-300)$ \\
\hline \multicolumn{5}{|l|}{ Previous glucocorticoid treatment (\%) } \\
\hline None & $75(57)$ & $43(57)$ & $23(58)$ & $9(56)$ \\
\hline In relation to chemotherapy & $26(20)$ & $17(23)$ & $6(15)$ & $3(19)$ \\
\hline Earlier from time to time & $16(12)$ & $8(11)$ & $5(15)$ & $2(13)$ \\
\hline Ongoing treatment & $6(5)$ & $3(4)$ & $2(5)$ & $1(6)$ \\
\hline In relation to radiotherapy & $8(5)$ & $4(5)$ & $3(8)$ & $1(6)$ \\
\hline $\begin{array}{l}\text { Number of plasma glucose measurements, } \\
\text { median (IQR) }\end{array}$ & $9(8-20)$ & $8(7-12)$ & $13(8-28)$ & $30(18-33)$ \\
\hline $\begin{array}{l}\text { Number of plasma glucose measurements until } \\
\text { time of diagnosis, median (IQR) }\end{array}$ & & & $6(3-8)$ & $7(4-15)$ \\
\hline Family history of diabetes $(\%)^{*}$ & $35(27)$ & $\begin{array}{l}18(24) \\
\quad N=73\end{array}$ & $\begin{array}{l}12(30) \\
\quad N=39\end{array}$ & $5(31)$ \\
\hline $\begin{array}{l}\text { Previous diabetes (glucocorticoid-induced or } \\
\text { gestational) }\end{array}$ & $1(0.8)$ & $1(1.3)$ & 0 & 0 \\
\hline
\end{tabular}

* $N$ indicates numbers of patients with data.

untreated DM and 1 did not develop DM. Further, one patient had overt unknown DM $(\mathrm{HbA} 1 \mathrm{c}=79 \mathrm{mmol} / \mathrm{mol})$ at baseline and needed insulin therapy. A high baseline HbA1c was associated with increased risk of glucocorticoid-induced DM both in univariate and multivariate logistic regression

$$
\begin{array}{lr}
\text { http://www.endocrineconnections.org } & \text { @2018 The authors } \\
\text { https://doi.org/10.1530/EC-18-0088 } & \text { Published by Bioscientifica Ltd }
\end{array}
$$

analyses (Table 2). The American Diabetes Association defines an $\mathrm{HbA} 1 \mathrm{c}$ value $\geq 39 \mathrm{mmol} / \mathrm{mol}$ as diagnostic for prediabetes (12). Using this cut-off as a predictive value for developing glucocorticoid-induced DM treated with insulin, the sensitivity was $86 \%$ (95\% CI: 67-100), the specificity

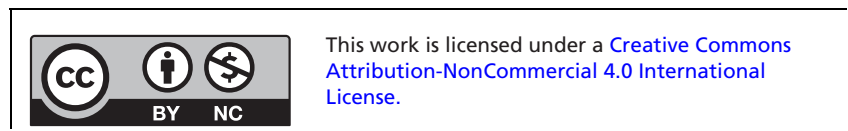




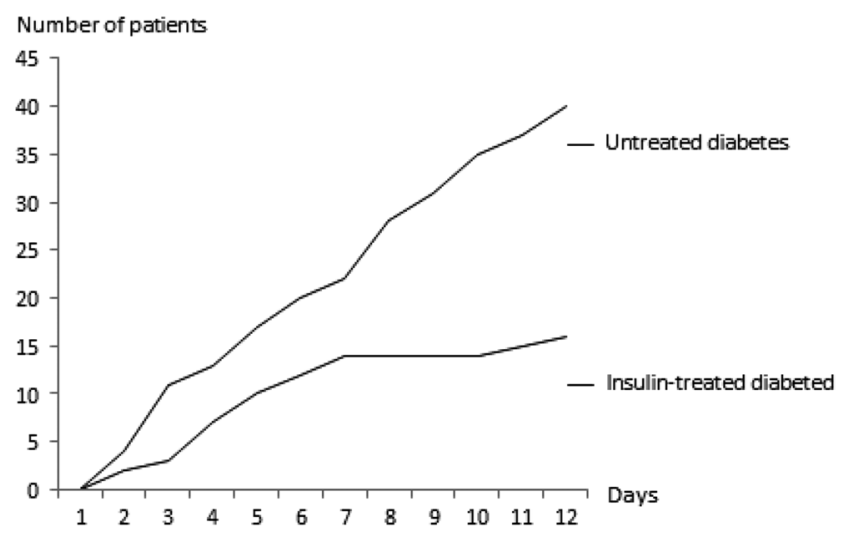

Figure 2

Time course of development of diabetes.

was 51\% (95\% CI: 42-61), the positive predictive value was 19\% (95\% CI: 9-29) and the negative predictive value was 96\% (95\% CI: 92-100). A total of 56 patients (43\%) had an HbA1c value below the cut-off value.

\section{Other risk factors}

In univariate analysis, baseline PS and baseline triglyceride levels were positively associated with developing insulintreated DM. In the multivariate analyses, only baseline HbA1c remained statistically significantly associated with developing insulin-treated DM. Odds ratio of developing insulin-treated DM per $1 \mathrm{mmol} / \mathrm{mol}$ change in HbA1c was $1.2(1.04-1.3 ; P=0.012)$ (Table 2$)$.

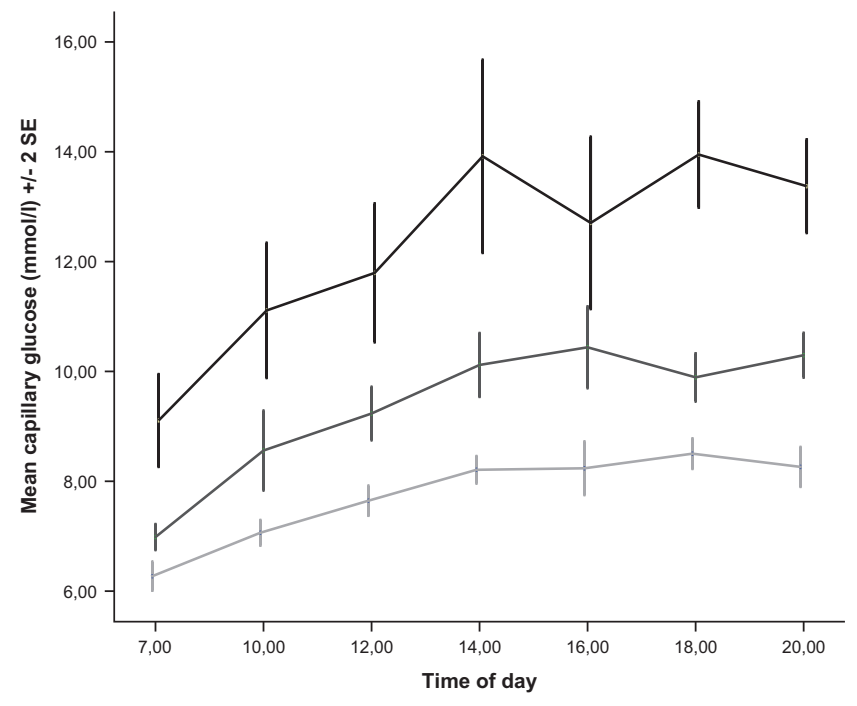

Figure 3

Plasma glucose measurements throughout the day in patients not developing diabetes, patients developing untreated diabetes and patients developing diabetes treated with insulin.

\section{Discussion}

In this prospective observational study in cancer patients receiving high-dose glucocorticoids, $43 \%$ of the patients developed DM and 12\% needed treatment with insulin to control glucose levels. Only one small prospective study with high-dose glucocorticoid treatment has previously been published (13). In that study of 35 patients with haematological diseases treated with at least $1 \mathrm{mg} / \mathrm{kg} /$ day of prednisolone $40.6 \%$ had developed DM at eight weeks (the definition of DM was fasting plasma glucose $\geq 7 \mathrm{mmol} / \mathrm{L}$ and/or postprandial plasma glucose $\geq 11.1 \mathrm{mmol} / \mathrm{L}$ ). No patients needed antidiabetic treatment. The plasma glucose monitoring was less intensive than that in our study with only four measurements every week for 8 or 12 weeks. In a retrospective survey of 80 patients with lymphoma treated with prednisolone $100 \mathrm{mg} /$ day for 5 days in each chemotherapy cycle, $32.5 \%$ developed glucocorticoidinduced DM and $3.75 \%$ was treated with insulin (ADA definition of DM: fasting plasma glucose $\geq 7.0 \mathrm{mmol} / \mathrm{L}$, random plasma glucose level $\geq 11.1 \mathrm{mmol} / \mathrm{L}$ accompanied by classical symptoms of hyperglycaemia). The intensity of plasma glucose measurements is not reported in the paper (14). The higher incidence of insulin-treated DM in our cohort may be explained by the closer monitoring of plasma glucose, a higher glucocorticoid dose, characteristics of the cohort and differences in clinical practice regarding treatment of glucocorticoid-induced DM. It is important to stress that the results of this study cannot be extrapolated to patients treated with substantially lower doses of glucocorticoids and to other patient types.

The finding that the majority of patients in our study needing insulin treatment were diagnosed within 7 days supports that glucocorticoid-induced DM develops rapidly. In accordance, a study with high-dose glucocorticoid treatment reported that $65.4 \%$ of the patients who developed DM were diagnosed during the first cycle of chemotherapy (14). Similarly, Fong et al. found that 94\% of 69 non-diabetic patients with malignant and nonmalignant disease developed hyperglycaemia within the first $48 \mathrm{~h}$ of treatment with medium dose glucocorticoids (prednisone $25 \mathrm{mg} /$ day) (15). In contrast, in studies with lower doses of glucocorticoid, DM developed throughout the entire treatment period $(13,14,16,17)$. This might be due to the monitoring practice with low-dose treatment where plasma glucose measurements are separated by many months.

The majority of patients who developed DM could probably have been identified within a few days if the screening had been even more thorough during the day.

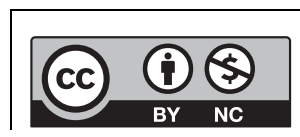

This work is licensed under a Creative Commons Attribution-NonCommercial 4.0 International License. 
Table 2 Univariate and multivariate logistic regression analyses with insulin-treated diabetes as dependent variable in 131 patients without known diabetes suffering from MSCC and treated with $\geq 100 \mathrm{mg}$ prednisolone per day.

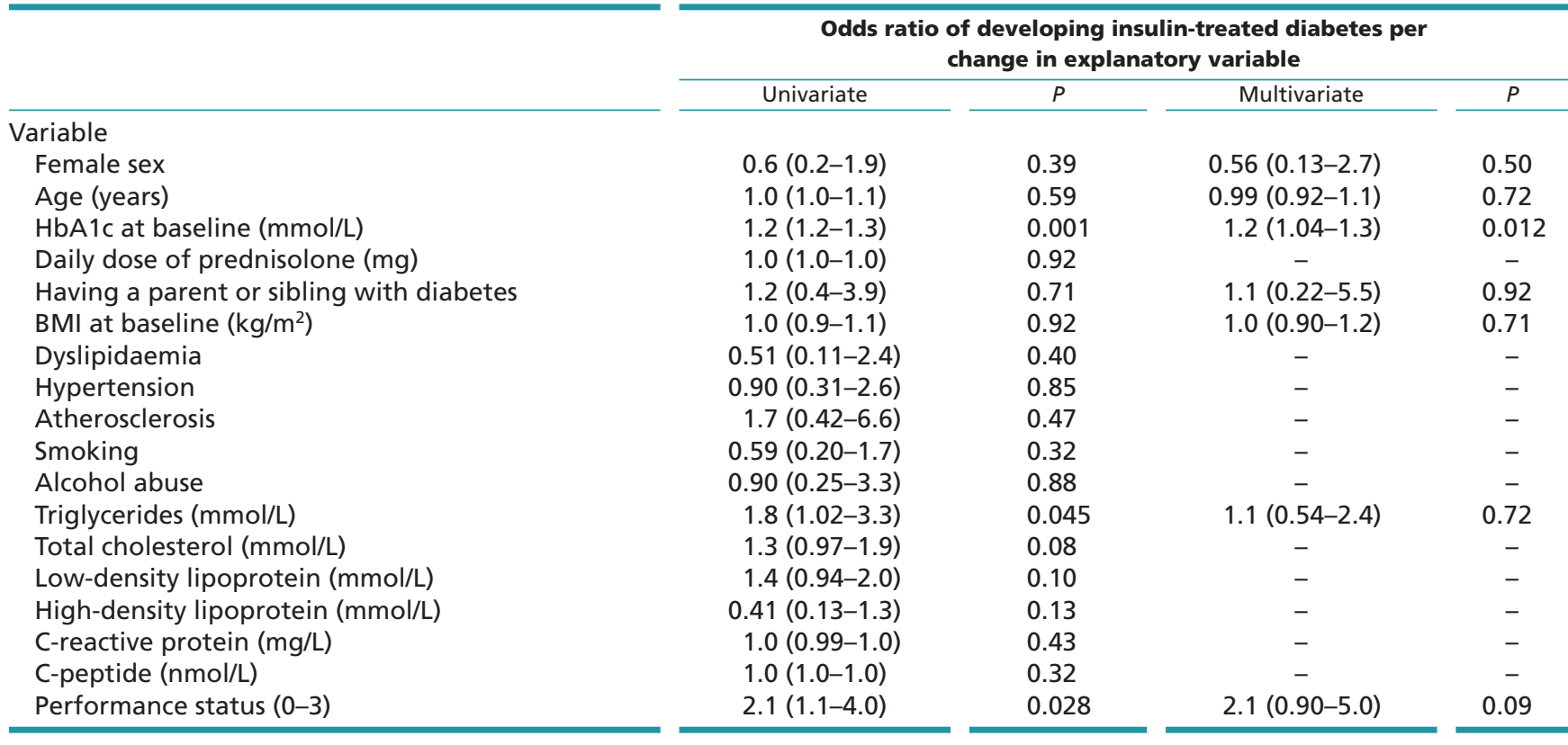

Odds ratio (95\% confidence intervals) of traditional risk factors for type 2 diabetes and other variables (explanatory variables) in univariate and multivariate logistic regression models with corticosteroid-induced insulin-treated diabetes as dependent variable. Established risk factors for type 2 diabetes (sex, age, HbA1c, BMI, having a parent or sibling with diabetes) and variables from the univariate analysis with a $P<0.15$ (only one of four lipid variables was chosen, since these variables are correlated) were included in the multivariate analysis.

At any time of the day - also during fasting - the glucose values seemed to be higher in the group of patients needing insulin. However, there was a substantial overlap of fasting glucose levels in the three groups making it difficult to use fasting glucose as a predictor for the trajectory of the glucose pattern for the rest of the day. Continuous subcutaneous glucose measurements may further elucidate the glucose profiles among patients with glucocorticoid-induced DM.

In multivariate analyses, we found $\mathrm{HbA1c}$ to be the only risk factor for developing DM after initiation of high-dose glucocorticoid treatment. A similar result was reported in a retrospective study on 128 patients with rheumatic or renal disease receiving pulse therapy with high-dose glucocorticoid (methylprednisolone $500-1000 \mathrm{mg} /$ day for 3 days). In that study, odds ratio for developing glucocorticoid-induced DM when HbA1c was above or equal to $6 \%(42 \mathrm{mmol} / \mathrm{mol})$, was 3.05 (18). In a retrospective survey of 80 patients with lymphoma treated with $100 \mathrm{mg} /$ day prednisone as part of chemotherapy in cycles of 5 days, it was reported that patients with an HbA1c level $>6.1 \%(43 \mathrm{mmol} / \mathrm{mol})$ had a hazard ratio of 9.35 for developing glucocorticoid-induced DM (15). We found that an $\mathrm{HbA1c}$-value below $39 \mathrm{mmol} / \mathrm{mol}$ (which is the American Diabetes Association cut-off for prediabetes)

$$
\text { http://www.endocrineconnections.org }
$$

was associated with a negative predictive value of $96 \%$ not to develop DM needing treatment with insulin. Applying this cut-off for further monitoring would in this population imply that we only had to screen half of our population with daily glucose measurements. It is not known if this cut-off value is applicable to other patient groups treated with glucocorticoids, since the negative predictive value depends on the prevalence of glucocorticoid-induced DM in a particular population. However, in similar populations measuring HbA1c before initiating high-dose glucocorticoid therapy may provide information about the risk of developing DM. It should, however, be kept in mind that erythrocyte turnover may be affected in cancer patients, for instance by the disease, by the chemotherapy or by blood transfusion, and this may hamper HbA1c interpretation.

Risk factors found in other studies of glucocorticoidinduced DM are age and BMI $(5,13,14,18,19)$. Additional risk factors proposed are dose of glucocorticoid $(5,20)$, family history of DM $(13,20)$ and hypertension (13). In our study population, we did not find age, BMI, hypertension or a family history of DM to be associated with developing DM. The reason for this is unclear. It was not possible to assess prednisolone dose as a risk factor in our study as the dose was almost similar in all patients. 


\section{Strengths and limitations}

Our prospective design allowed us to gather information of possible risk factors for DM, collect blood samples and take the medical history. Moreover, we included the number of patients predicted from our sample size calculation and found that the incidence of DM (43\%) was higher than expected. Hence, we regard the statistical power of the study satisfactory. Compared to other studies, the plasma glucose monitoring intensity in the present study is a strength. However, we may still have misclassified some patients as non-diabetic, especially if glucose measurements were done in the morning or were very few. Therefore, the number of patients developing DM in our study should be regarded as a conservative estimate. Moreover, classification of patients as needing treatment with insulin was not guideline-driven but based on the decision according to local practice. Hence, the classification of patients reflects everyday clinical practice and in many settings no strict rules for antidiabetic treatment of glucocorticoid-induced hyperglycemia exist.

\section{Conclusions}

In our study, a substantial proportion of the patients developed insulin-treated DM as a result of high-dose glucocorticoid therapy. Glucocorticoid-induced DM may, if left untreated, cause substantial morbidity. Therefore, screening for hyperglycaemia before and during treatment with glucocorticoids is rational.

However, at present, there is no consensus about a screening strategy. The American Endocrine Society Clinical Practice Guideline (7) recommends laboratory blood glucose testing on admission for all inpatients and continued testing for patients receiving glucocorticoid therapy. If all blood glucose results are below $7.8 \mathrm{mmol} / \mathrm{L}$ for a period of at least $24-48 \mathrm{~h}$ the testing may be discontinued. The Joint British Diabetes Societies for inpatient care, JBDS-IP recommends HbA1c testing prior to commencement of glucocorticoid treatment in patients perceived to be at high risk (not defined) of glucocorticoidinduced DM and subsequent blood glucose monitoring at least once daily in the afternoon or evening when plasma glucose values are highest (6).

Our data on patients with MSCC challenge these guidelines in different ways. Firstly, HbA1c testing in all patients will identify half of the patients as highrisk patients ( $\mathrm{HbA} 1 \mathrm{C} \geq 39 \mathrm{mmol} / \mathrm{mol}$ ) who need further monitoring and half of the patients as low-risk patients who can be spared continued blood glucose testing. Secondly, we identified the majority of patients who needed insulin treatment to control blood glucose within the first week and had the testing been stopped within 24-48 h some might have been missed.

We suggest a two-step screening procedure using an initial HbA1c measurement to identify high-risk patients to be followed with glucose measurements. This approach warrants prospective testing in other cohorts.

\section{Declaration of interest}

The authors declare that there is no conflict of interest that could be perceived as prejudicing the impartiality of the research reported.

\section{Funding}

Research Foundation of Nordsjællands Hospital, The Tvergaard Foundation, Fru Olga Bryde Nielsen Foundation, Kaptajnløjtnant Harald Jensen og Hustrus Foundation.

\section{Acknowledgements}

The staff at the Trauma Centre and at the Department of Radiation Oncology at Rigshospitalet are thanked for competent and supportive assistance.

\section{References}

1 van Raalte DH \& Diamant M. Steroid diabetes: from mechanism to treatment? Netherlands Journal of Medicine 201472 62-72.

2 Ellis ME, Weiss RB, Korzun AH, Rice MA, Norton L, Perloff M, Lesnick GJ \& Wood WC. Hyperglycemic complications associated with adjuvant chemotherapy of breast cancer. A cancer and leukemia group B (CALGB) study. American Journal of Clinical Oncology 19869 533-536. (https://doi.org/10.1097/00000421-198612000-00013)

3 Jensen K, Steinthorsdottir KJ \& Brandt B. In-hospital cardiac arrest due to unobserved steroid-induced hyperglycaemic hyperosmolar syndrome. Ugeskrift for Laeger 2013175 1044-1045.

4 Weiser MA, Cabanillas ME, Konopleva M, Thomas DA, Pierce SA, Escalante CP, Kantarjian HM \& O'Brien SM. Relation between the duration of remission and hyperglycemia during induction chemotherapy for acute lymphocytic leukemia with a hyperfractionated cyclophosphamide, vincristine, doxorubicin, and dexamethasone/methotrexate-cytarabine regimen. Cancer 2004100 1179-1185. (https://doi.org/10.1002/cncr.20071)

5 Harris D, Barts A, Connors J, Dahl M, Elliott T, Kong J, Keane T, Thompson D, Stafford S, Ur E, et al. Glucocorticoid-induced hyperglycemia is prevalent and unpredictable for patients undergoing cancer therapy: an observational cohort study. Current Oncology 201320 e532-e538. (https://doi.org/10.3747/co.20.1499)

6 Joint British Diabetes Societies for Inpatient Care. Management of Hyperglycaemia and Steroid (Glucocorticoid) Therapy. Norwich, UK: JBDS-IP, 2014. (available at: http://www.diabetologists-abcd.org.uk/ JBDS/JBDS_IP_Steroids.pdf)

7 Umpierrez GE, Hellman R, Korytkowski MT, Kosiborod M, Maynard GA, Montori VM, Seley JJ, Van den Berghe G \& Endocrine Society. Management of hyperglycemia in hospitalized patients in non-critical care setting: an endocrine society clinical practice guideline. Journal of Clinical Endocrinology and Metabolism 201297 16-38. (https://doi.org/10.1210/jc.2011-2098)

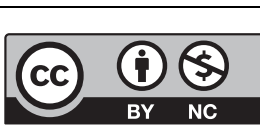


8 Sorensen S, Helweg-Larsen S, Mouridsen H \& Hansen HH. Effect of high-dose dexamethasone in carcinomatous metastatic spinal cord compression treated with radiotherapy: a randomised trial. European Journal of Cancer 1994 30A 22-27. (https://doi.org/10.1016/S09598049(05)80011-5)

9 Oken MM, Creech RH, Tormey DC, Horton J, Davis TE, McFadden ET $\&$ Carbone PP. Toxicity and response criteria of the Eastern Cooperative Oncology Group. American Journal of Clinical Oncology 19825 649-655. (https://doi.org/10.1097/00000421-19821200000014)

10 World Health Organization/International Diabetes Federation. Definition and Diagnosis of Diabetes Mellitus and Intermediate Hyperglycemia. Geneva, Switzerland: WHO/IDF, 2006. (available at: www.who.int/diabetes/publications/Definition\%20and\%20 diagnosis\%20of\%20diabetes_new.pdf)

11 Morgen SS, Nielsen DH, Larsen CF, Sogaard R, Engelholm SA \& Dahl B. Moderate precision of prognostic scoring systems in a consecutive, prospective cohort of 544 patients with metastatic spinal cord compression. Journal of Cancer Research and Clinical Oncology 2014140 2059-2064. (https://doi.org/10.1007/s00432-0141776-2)

12 American Diabetes Association. Diagnosis and classification of diabetes mellitus. Diabetes Care 201437 (Suppl 1) S81-S90. (https:// doi.org/10.2337/dc14-S081)

13 Gonzalez-Gonzalez JG, Mireles-Zavala LG, Rodriguez-Gutierrez R, Gomez-Almaguer D, Lavalle-Gonzalez FJ, Tamez-Perez HE, GonzalezSaldivar G \& Villarreal-Perez JZ. Hyperglycemia related to high-dose glucocorticoid use in noncritically ill patients. Diabetology and Metabolic Syndrome 20135 18. (https://doi.org/10.1186/1758-5996-5-18)
14 Lee SY, Kurita N, Yokoyama Y, Seki M, Hasegawa Y, Okoshi Y \& Chiba S. Glucocorticoid-induced diabetes mellitus in patients with lymphoma treated with CHOP chemotherapy. Supportive Care in Cancer 201422 1385-1390. (https://doi.org/10.1007/s00520-0132097-8)

15 Fong AC \& Cheung NW. The high incidence of steroid-induced hyperglycaemia in hospital. Diabetes Research and Clinical Practice 201399 277-280. (https://doi.org/10.1016/j.diabres.2012.12.023)

16 Kim SY, Yoo CG, Lee CT, Chung HS, Kim YW, Han SK, Shim YS \& Yim JJ. Incidence and risk factors of steroid-induced diabetes in patients with respiratory disease. Journal of Korean Medical Science 201126 264-267. (https://doi.org/10.3346/jkms.2011.26.2.264)

17 Panthakalam S, Bhatnagar D \& Klimiuk P. The prevalence and management of hyperglycaemia in patients with rheumatoid arthritis on corticosteroid therapy. Scottish Medical Journal 200449 139-141. (https://doi.org/10.1177/003693300404900407)

18 Katsuyama T, Sada KE, Namba S, Watanabe H, Katsuyama E, Yamanari T, Wada J \& Makino H. Risk factors for the development of glucocorticoid-induced diabetes mellitus. Diabetes Research and Clinical Practice 2015108 273-279. (https://doi.org/10.1016/j. diabres.2015.02.010)

19 Uzu T, Harada T, Sakaguchi M, Kanasaki M, Isshiki K, Araki S, Sugiomoto T, Koya D, Haneda M, Kashiwagi A, et al. Glucocorticoidinduced diabetes mellitus: prevalence and risk factors in primary renal diseases. Nephron Clinical Practice 2007105 c54-c57. (https:// doi.org/10.1159/000097598)

20 Raul Ariza-Andraca C, Barile-Fabris LA, Frati-Munari AC \& BaltazarMontufar P. Risk factors for steroid diabetes in rheumatic patients. Archives of Medical Research 199829 259-262.

Received in final form 4 April 2018

Accepted 18 April 2018

Accepted Preprint published online 18 April 2018 http://www.endocrineconnections.org https://doi.org/10.1530/EC-18-0088
(2)18 The authors Published by Bioscientifica Ltd

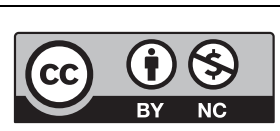

This work is licensed under a Creative Commons Attribution-NonCommercial 4.0 International License. 